shown how to prevent denervation of the facial nerve by injections of corticotrophin (ACTH) for ten days soon after the onset of palsy.

Surgical decompression is painful and requires considerable experience for its safe performance. It still remains a controversial procedure.

\section{Airborne Transmission of Smallpox}

For nearly a hundred years the aerial spread of smallpox virus has been one of the great medical controversies. It is generally accepted that the person suffering from smallpox does not become infectious until just before the first macules of the exanthematous rash begin to appear. At this stage the lesions on the mucous membrane of the upper respiratory tract are breaking down and releasing large quantities of virus into the air. Epidemiologically it has been shown that the patient is most infectious in the early eruptive stage of the rash and that coughing increases the volume of virus expelled.

Extensive studies have shown that most patients with smallpox are infected either by "face-to-face" contact or by contact with infected fomites. As the person suffering from smallpox is likely to be ill when he becomes infectious, it has been thought that with adequate isolation there is little danger of the spread of the disease. Yet in the past during several outbreaks cases of smallpox have occurred where no possibility of contact could be established. Such cases were often in the neighbourhood of smallpox hospitals or in different parts of passenger liners. Although many experts accepted aerial convection as a possibility, it was considered that the hypothesis was probably incapable of direct proof. But now an outbreak in Meschede, Federal Republic of Germany, ${ }^{12}$ would appear to indicate fairly conclusively that aerial transmission of smallpox does occur under certain conditions. Although it is a rare event, it has a special importance to epidemiologists and hospital administrators.

A German electrician recently returned from Karachi was admitted to the isolation ward of a large general hospital with pyrexia and suspected to be suffering from typhoid fever. Four days after admission a rash appeared, and two days later, when the diagnosis of mallpox was confirmed, he was transferred to a smallpox hospital. In spite of fairly rigorous isolation of the patient, and immediate immunization of all the staff and patients in the general hospital, 20 cases of smallpox occurred, with four deaths. The patient never left his cubicle during the six days he was in the hospital and had no contact with the other patients who contracted the disease. One of the infected persons was a visitor who spent only 15 minutes in the entrance hall talking to a physician. Another case was one of the nursing sisters who had been ill for some time in the top floor of the hospital and had not left her sickroom during the whole sojourn of the original case. The distribution of the cases in the various parts of the hospital together with a smoke test of the air movement in the building under similar atmospheric conditions strongly suggested aerial convection.

The evidence in the Meschede outbreak is fairly conclusive, but whether it can be considered sufficient to give plausibility to airborne transmission over long distances must

1 W.H.O. Weekly Epidemiological Record, 1970, 45, 249.

2 W.H.O. Chronicle, 1970, 24, 311. remain a matter of conjecture. Nevertheless, the outbreak shows that smallpox is an ever present risk to any general hospital, especially in these days of popular air travel. The safeguards must be, firstly, a well-immunized hospital staff, and, secondly, a sound isolation procedure for all cases of undiagnosed pyrexial illness. But probably the most important lesson of the Meschede outbreak is the need to consider carefully the siting of isolation accommodation if it is to be part of a main hospital building, and for some regard to be paid to the movement of air currents in hospitals. Although aerial convection of virus particles may be uncommon, the insistence of our predecessors in keeping isolation accommodation separate may merit some reconsideration by our hospital planners.

\section{Depression and Oral Contraception}

There is now a sufficient body of evidence to establish a relationship between the use of oral contraceptives and the occurrence of depression..$^{1-7}$ The relationship is complex and depends on the physical and psychological predisposition of the woman as well as on the properties of the contraceptive itself.

Depression can have serious consequences for a patient and her family. Despite this the consensus of published opinion suggests that as many as $6-7 \%$ of women suffer depressive symptoms while taking an oral contraceptive compared to $1-2 \%$ of controls. Some attempt suicide, and in many the cause of the depression is not recognized. ${ }^{6}$ But since oral contraceptives are the most effectual form of contraception for most women it is important to learn how to recognize those women who may be particularly at risk. Unfortunately most investigators of this problem have encountered methodological difficulties. Few studies have been prospective, and adequate controls have been hard to provide. There are also difficulties in defining and quantifying depression and in comparing the results of one study with another.

The controlled comparison reported by Dr. Brenda $\mathrm{N}$. Herzberg and her colleagues in this issue of the B.M. $\mathcal{F}$. (page 142) is of interest in showing by a reliable and valid subjective measure that $6.6 \%$ of women taking oral contraceptives were more severely depressed than any women in a group using physical methods of contraception. They also show that the point during the menstrual cycle at which this assessment is made is important. This has been overlooked in most studies. On the other hand they found little correlation between the type of oral contraceptive and incidence of depressive symptoms and therefore little correlation between progestogenic activity and depressant effect. This finding differs from others, ${ }^{56}$ which have shown that the greater the progestogenic activity the more likely will depression be induced.

How should the prescriber try to prevent a depressive

1 Kaye, B. M., Fournal of the American Medical Association, 1963, 186, 522.

2 Hauser, G. A., and Schubiger, V., Archiv für Gynäkologie, 1965, 202, 175. Kane, F. J., Daly, R. J., Ewing, J. A., and Keeler, M. H., British fournal of Psychiatry, 1967, 113, 265.

Nilsson, A., Jacobson, J., and Ingemanson, C. A., Acta Obstetrica et Gynecologia Scandinavica, 1967, 46, 537.

5 Grant, E. C. G., and Pryse-Davies, J., British Medical fournal, 1968, 3,

- Lewis, A., and Hoghughi, M., British fournal of Psychiatry, 1969, 115, 697.

Herzberg, B., and Coppen, A., British Fournal of Psychiatry, 1970, 116, 161. 